\title{
A!
}

This is an electronic reprint of the original article.

This reprint may differ from the original in pagination and typographic detail.

Chen, Kexun; Pasanen, Toni; Vähänissi, Ville; Savin, Hele

\section{Effect of MACE Parameters on Electrical and Optical Properties of ALD Passivated Black Silicon}

Published in:

IEEE Journal of Photovoltaics

DOI:

10.1109/JPHOTOV.2019.2917787

Published: 01/07/2019

Document Version

Peer reviewed version

Please cite the original version:

Chen, K., Pasanen, T., Vähänissi, V., \& Savin, H. (2019). Effect of MACE Parameters on Electrical and Optical Properties of ALD Passivated Black Silicon. IEEE Journal of Photovoltaics, 9(4), 974-979. [8728144].

https://doi.org/10.1109/JPHOTOV.2019.2917787

This material is protected by copyright and other intellectual property rights, and duplication or sale of all or part of any of the repository collections is not permitted, except that material may be duplicated by you for your research use or educational purposes in electronic or print form. You must obtain permission for any other use. Electronic or print copies may not be offered, whether for sale or otherwise to anyone who is not an authorised user. 


\title{
Effect of MACE Parameters on Electrical and Optical Properties of ALD Passivated Black Silicon
}

\author{
Kexun Chen ${ }^{\dagger}$, Toni P. Pasanen ${ }^{\dagger}$, Ville Vähänissi, and Hele Savin
}

\begin{abstract}
Metal-assisted chemical etching (MACE) enables efficient texturing of diamond-wire sawn multicrystalline silicon (mc-Si) wafers. However, the excellent optics are often sacrificed by polishing the surface to achieve better surface passivation with chemical-vapor-deposited (CVD) silicon nitride $\left(\mathrm{SiN}_{x}\right)$. In this work, we show that a polishing step is not required when CVD $\mathrm{SiN}_{x}$ is replaced with atomic-layer-deposited (ALD) aluminum oxide $\left(\mathrm{Al}_{2} \mathrm{O}_{3}\right)$. Indeed, while polishing increases reflectance, it has in general only very modest effect on surface recombination velocity of ALD-passivated b-Si. Furthermore, since $A L D \mathrm{Al}_{2} \mathrm{O}_{3}$ is compatible with various surface morphologies due to its excellent conformality, the MACE parameters can be more freely adjusted. First, the concentration of silver nitrate $\left(\mathrm{AgNO}_{3}\right)$ in $\mathrm{AgNO}_{3} / \mathrm{H}_{2} \mathrm{O}$ solution that is used to deposit Ag nanoparticles is shown to affect the final b-Si morphology. Instead of needle-shaped b-Si produced by $5 \mathrm{mmol} / \mathrm{L} \mathrm{AgNO}_{3}$ concentration, two orders of magnitude lower $\mathrm{AgNO}_{3}$ concentration produces porous structures, which are more challenging to passivate. Additionally, we demonstrate that a separate Ag nanoparticle removal step in nitric acid $\left(\mathrm{HNO}_{3}\right)$ is not a prerequisite for high carrier lifetime. Instead, Ag nanoparticles present during polishing in a $\mathrm{HF} / \mathrm{HNO}_{3} / \mathrm{H}_{2} \mathrm{O}$ solution affect the final b-Si morphology by accelerating the etching of $\mathrm{Si}$. The results demonstrate that no trade-offs are necessary between optical and electrical properties of MACE b-Si when using ALD.
\end{abstract}

Index Terms-black silicon, nanostructure, metal assisted chemical etching, atomic layer deposition

\section{INTRODUCTION}

$\mathrm{M}$ ETAL-ASSISTED chemical etching (MACE) has high potential to become the mainstream texturing method for multicrystalline silicon (mc-Si) substrates, since it is able to efficiently reduce reflectance of diamond-wire sawn wafers [1]. Indeed, MACE-textured surfaces are often called black silicon (b-Si) due to their dark appearance, and hence, MACE b-Si has raised interest also as a more efficient texture for monocrystalline wafers. Furthermore, the technique can easily be adopted to existing solar cell production lines without the need for large investment to new equipment due to its wet-

Manuscript received February 7, 2019. The work of T. P. Pasanen was supported by the Aalto ELEC Doctoral School, Jenny and Antti Wihuri Foundation, Walter Ahlström Foundation, and the Foundation of Electronic Engineers. (Kexun Chen and Toni P. Pasanen contributed equally to this work.) (Corresponding author: Toni P. Pasanen.) chemical nature [2], [3]. However, the MACE-texture currently remains non-optimized from the optics perspective, since the nanostructures are typically polished to enable better conformality, and hence, more efficient surface passivation using chemical vapour deposited (CVD) silicon nitride $\left(\mathrm{SiN}_{x}\right)$ [4]-[6], which is widely used by the current PV industry. Due to polishing, reflectance of MACE-textured wafers remains as high as $15-30 \%$ without anti-reflection (AR) coatings, and a thick $\mathrm{SiN}_{x}$ film is required to reduce reflectance to $\sim 8-10 \%$ [5], [6]. Surface passivation of MACE-structures with lower, $<5 \%$ reflectance has been demonstrated with thermally-grown silicon dioxide $\left(\mathrm{SiO}_{2}\right)$ [7], [8]. Although thermal $\mathrm{SiO}_{2}$ grows conformally on nanostructures, the passivation efficiency is limited due to negligible density of fixed charges in the thin film [9]. Moreover, high-temperature oxidation after the MACE process increases the risk of metal contamination.

The challenges related to either conformality or high process temperature can be overcome by the application of atomic layer deposition (ALD). Indeed, excellent surface passivation has been obtained on dry-etched high-aspect-ratio b-Si using ALD aluminium oxide $\left(\mathrm{Al}_{2} \mathrm{O}_{3}\right)$ [9], [10], also with an industry-scalable spatial ALD system [11]. Hence, the polishing step can likely be omitted, or at least substantially shortened, by replacing $\mathrm{SiN}_{x}$ with $\mathrm{ALD} \mathrm{Al}_{2} \mathrm{O}_{3}$, which improves the optical performance of the final device. Although most of the reports on MACE b-Si have concentrated on $\mathrm{SiN}_{x}$, the excellence of $\mathrm{ALD} \mathrm{Al}_{2} \mathrm{O}_{3}$ has been demonstrated in a few recent studies [12]-[16]. Rahman et al. reported surface recombination velocity (SRV) of $26 \mathrm{~cm} / \mathrm{s}$ in silicon nanowires with $6 \%$ reflectance [12], whereas Chong et al. achieved even better surface passivation using slightly shallower nanostructures with a combination of $\sim 19 \mathrm{~cm} / \mathrm{s} \mathrm{SRV}$ and $\sim 7 \%$ reflectance [13]. Additionally, Parashar et al. recently demonstrated SRV of only $\sim 5 \mathrm{~cm} / \mathrm{s}$ on $50 \mu \mathrm{m}$ thick flexible b$\mathrm{Si}$ substrates using a nitrogen-doped $\mathrm{Al}_{2} \mathrm{O}_{3}$ thin film [16]. However, most of the studies have optimized the MACE parameters and the resulting $\mathrm{b}$-Si morphology only from the optics perspective [17], [18], and disregarded surface passivation. Moreover, since the effect of MACE parameters on

All authors are with the Department of Electronics and Nanoengineering, Aalto University, 02150 Espoo, Finland (e-mail: kexun.chen@aalto.fi; toni.pasanen@aalto.fi; ville.vahanissi@aalto.fi; hele.savin@aalto.fi) 
electrical properties has earlier been discussed from the $\mathrm{SiN}_{x}$ passivation perspective, the application of $\mathrm{ALD} \mathrm{Al}_{2} \mathrm{O}_{3}$ enables the possibility to optimize the parameters further to achieve more efficient combination of reflectance and SRV. The first demonstration by Chong et al. showed that SRV is surprisingly independent of the surface area enlargement of the MACE nanostructure, which was determined by the polishing time [13], but the effect of other process parameters, such as concentration of the solutions, remains ambiguous.

Although silver generates less electrically active deep-level defects in silicon than gold or copper, its involvement in the MACE process increases the risk of contamination due to its high diffusivity [19], [20]. Therefore, the nanoparticles are typically removed in $\mathrm{HNO}_{3}$ after the nanotexturing process to prevent contaminating the bulk during following high temperature process steps, such as contact firing [5]-[7], [18], [21]. Nevertheless, a simplified process would result in faster throughput and cost savings, and hence, the exclusion of a separate Ag removal step would be favored.

In this paper, we study experimentally if the polishing step can be omitted by replacing $\mathrm{SiN}_{x}$ with ALD $\mathrm{Al}_{2} \mathrm{O}_{3}$. Additionally, we investigate the effect of silver nitrate $\left(\mathrm{AgNO}_{3}\right)$ concentration in $\mathrm{AgNO}_{3} / \mathrm{H}_{2} \mathrm{O}$ solution, which is used to deposit Ag nanoparticles, on optical and electrical properties of ALDpassivated MACE b-Si. We also try to simplify the nanotexturing process by studying, whether an Ag removal step in $\mathrm{HNO}_{3}$ is necessary to obtain good electrical performance required for high-efficiency solar cells. To address these research questions, we first investigate the morphology of the b-Si samples fabricated using various etching parameters. We continue by analysing the optics of the MACE-textures, and finally, evaluate the efficiency of ALD surface passivation and whether metal contamination is an issue in the same nanostructured samples.

\section{EXPERIMENTAL}

Samples used in this study were quarters of 4" shiny-etched boron-doped p-type high-quality float-zone (FZ) silicon wafers (1 $\Omega \mathrm{cm}, 250 \mu \mathrm{m},(100)$ orientation). The experimental process flow is presented in Fig. 1. A three-step MACE-process was used to enhance control over surface morphology [2], [13], [21]. First, Ag nanoparticles were deposited electrolessly by immersing hydrofluoric acid (HF)-treated samples in a $\mathrm{AgNO}_{3} / \mathrm{H}_{2} \mathrm{O}$ solution with either $0.05 \mathrm{mmol} / \mathrm{L}$ or $5 \mathrm{mmol} / \mathrm{L}$ concentration of $\mathrm{AgNO}_{3}$ (labelled "low $\left[\mathrm{AgNO}_{3}\right]$ " or "high $\left[\mathrm{AgNO}_{3}\right]$ ", respectively) for $20 \mathrm{~s}$. Two clearly distinct $\mathrm{AgNO}_{3}$ concentration levels were selected to limit the number of different variable combinations. The b-Si nanotexture was formed on both sides of the samples by a 2 min dip in a $\mathrm{HF} / \mathrm{H}_{2} \mathrm{O}_{2} / \mathrm{H}_{2} \mathrm{O}$ solution $\left(\mathrm{HF}(50 \%): \mathrm{H}_{2} \mathrm{O}_{2}(30 \%): \mathrm{H}_{2} \mathrm{O}=\right.$ 25:10:270; v:v:v) at room temperature under normal cleanroom lighting. Subsequently, the Ag nanoparticles were removed from half of the samples by immersing them in $69 \% \mathrm{HNO}_{3}$ for $10 \mathrm{~min}$, while the nanoparticles were left on the other half of the samples for the rest of the process (labelled "with $\mathrm{Ag}$ removal" or "without Ag removal", respectively). The nanostructure fabrication was finished by polishing in a $\mathrm{HF} / \mathrm{HNO}_{3} / \mathrm{H}_{2} \mathrm{O}$ solution $\left(\mathrm{HF}(50 \%): \mathrm{HNO}_{3}(69 \%): \mathrm{H}_{2} \mathrm{O}=\right.$

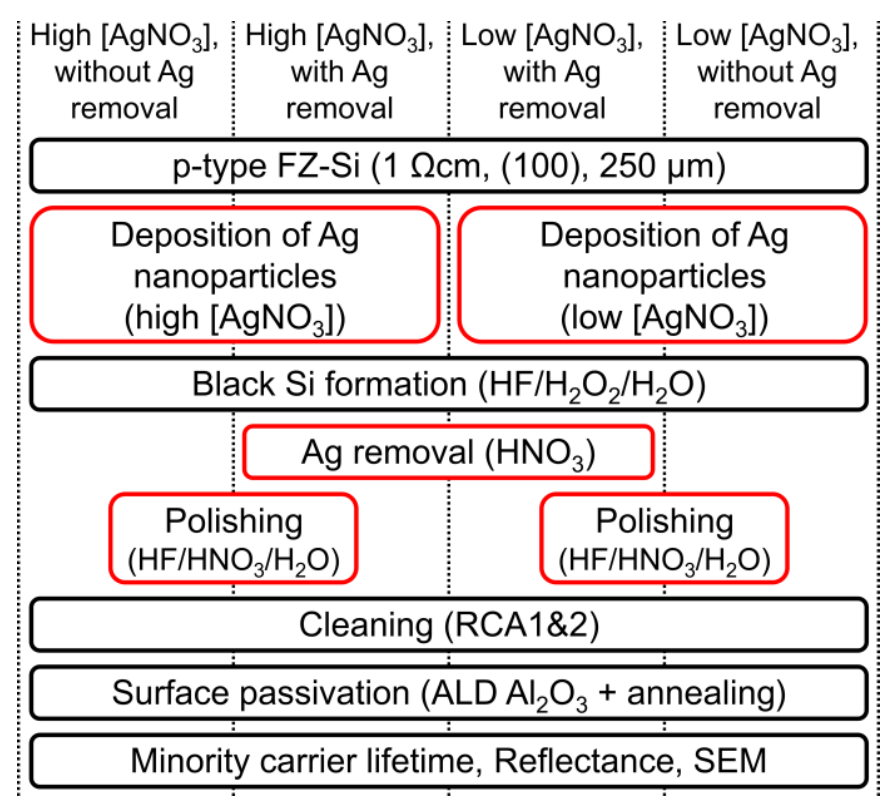

Fig. 1. Experimental procedure. The steps that have varied parameters are highlighted in red. Labels used in the subsequent figures are reported on the top.

3:50:70; v:v:v) for $0 \mathrm{~s}$ (i.e., no polishing), $30 \mathrm{~s}$, or $60 \mathrm{~s}$ and rinsing in de-ionized water. Finally, the samples were dried using a nitrogen gun.

After the MACE process, the samples were cleaned with the RCA cleaning sequence. To enhance the stability and effectiveness of the bath, a commonly-used complexing agent, 1,2-cyclohexanediaminetetraacetic acid (CDTA), was added to the RCA1 solution [22], [23]. The oxide grown during the cleaning was left on the sample surfaces. Subsequently, the surfaces were passivated with double-sided ALD $\mathrm{Al}_{2} \mathrm{O}_{3}$ deposited at $200{ }^{\circ} \mathrm{C}$ using a TMA $/ \mathrm{H}_{2} \mathrm{O}$-based process and Beneq TFS 500 tool, similar to reported in [24]. Surface passivation was activated by a 30 -minute annealing at $400{ }^{\circ} \mathrm{C}$ in nitrogen.

The samples were characterized by minority charge carrier lifetime measured with quasi-steady state photoconductance (QSSPC) technique (Sinton WCT-120) to evaluate the performance of surface passivation and to observe, whether possible metal contamination deteriorates the electrical quality of the bulk. In addition, the optical properties were evaluated by integrating sphere-based surface reflectance measurements (Agilent Cary 5000). Average reflectance ( $\left.R_{\text {ave }}\right)$ weighted by the AM1.5G solar spectrum was calculated in the wavelength range of 300-1000 nm using equation

$R_{\mathrm{ave}}=\sum_{\lambda_{i}=300 \mathrm{~nm}}^{1000 \mathrm{~nm}}\left[\frac{I\left(\lambda_{i}\right)}{I_{\mathrm{tot}}} \cdot R\left(\lambda_{i}\right)\right]$

where $\lambda_{i}$ is a single wavelength, $R\left(\lambda_{i}\right)$ and $I\left(\lambda_{i}\right)$ are the reflectance and spectral irradiance at the wavelength $\lambda_{i}$, respectively, and $I_{\text {tot }}$ is the total irradiance in the inspected wavelength range, given by 
$I_{\text {tot }}=\sum_{\lambda_{i}=300 \mathrm{~nm}}^{1000 \mathrm{~nm}} I\left(\lambda_{i}\right)$.

Finally, the morphology of the MACE nanostructures was imaged by scanning electron microscopy (SEM, Zeiss Supra 40). Uncertainty of $5 \%$ was assumed in both QSSPC and reflectance measurements.

\section{RESULTS AND DISCUSSION}

\section{A. Surface morphology}

The study investigates first the effect of MACE-parameters on b-Si morphology. Fig. 2 presents cross-sectional SEM images of the b-Si samples prior to $(0 \mathrm{~s})$ and after $30 \mathrm{~s}$ or $60 \mathrm{~s}$ of polishing. Within the samples without polishing, the $\mathrm{AgNO}_{3}$ concentration in the $\mathrm{AgNO}_{3} / \mathrm{H}_{2} \mathrm{O}$ solution has a prominent effect on the b-Si morphology. High $\left[\mathrm{AgNO}_{3}\right]$ produces needleshaped $b-\mathrm{Si}$, whereas low $\left[\mathrm{AgNO}_{3}\right]$ results in smaller and more porous nanostructures, which are likely more challenging to passivate. Similar observations have been reported also in earlier studies, which attributed the increasing porosity to reduced size and increased surface coverage of $\mathrm{Ag}$ nanoparticles with decreasing $\mathrm{AgNO}_{3}$ concentration [17], [18].

Polishing in $\mathrm{HF} / \mathrm{HNO}_{3} / \mathrm{H}_{2} \mathrm{O}$ solution smoothens the nanostructures in all samples, which is natural, since the step is typically applied to modify the MACE texture to better suit for CVD $\mathrm{SiN}_{x}$. Opposite to $\mathrm{H}_{2} \mathrm{O}_{2}$ that was used in the b-Si formation step, $\mathrm{HNO}_{3}$ efficiently oxidizes silicon also without metal catalyst, and the grown oxide is simultaneously removed by HF [25], [26]. Consequently, silicon is etched from all

$$
0 \mathrm{~s} \quad 30 \mathrm{~s}
$$

surfaces that are in contact with the chemicals and the average height of the b-Si nanostructures in the high $\left[\mathrm{AgNO}_{3}\right]$ samples reduces from $\sim 320 \mathrm{~nm}$ to $\sim 250 \mathrm{~nm}$ and $\sim 125 \mathrm{~nm}$ during $30 \mathrm{~s}$ and $60 \mathrm{~s}$ polishing, respectively. Correspondingly, polishing removes the porous layer from the low $\left[\mathrm{AgNO}_{3}\right]$ samples and the surface structures gradually turn more similar to those on the high $\left[\mathrm{AgNO}_{3}\right]$ samples. Indeed, after $60 \mathrm{~s}$ polishing, all samples start to resemble each other rather closely independent of the used $\mathrm{AgNO}_{3}$ concentration. Moreover, another similar set of samples was polished for $180 \mathrm{~s}$, and all surfaces became virtually flat independent of the $\mathrm{AgNO}_{3}$ concentration or the presence of the Ag removal step. Hence, the 180 s samples were excluded from further inspection.

In the presence of $\mathrm{Ag}$ nanoparticles (i.e., "without $\mathrm{Ag}$ removal"), polishing produces slightly shallower and wider nanostructures than in the case, where the nanoparticles have been removed prior to the polishing step. This observation indicates that silver catalyzes the etching also in this solution, but the chemical mechanism is different from the $\mathrm{b}-\mathrm{Si}$ formation step. When the HF concentration is sufficiently high compared to that of the oxidizing agent, such as $\mathrm{H}_{2} \mathrm{O}_{2}$ or $\mathrm{HNO}_{3}$, all electron holes generated at the nanoparticles are consumed at the $\mathrm{Ag}$-Si interface and etching occurs only at the vicinity of $\mathrm{Ag}$ [3], [7], [27]. This is the case in the used $\mathrm{HF} / \mathrm{H}_{2} \mathrm{O}_{2} / \mathrm{H}_{2} \mathrm{O}$ solution, and nanostructures or nanopores form. Instead, when the relative $\mathrm{HF}$ concentration is low, as in the $\mathrm{HF} / \mathrm{HNO}_{3} / \mathrm{H}_{2} \mathrm{O}$ solution, consumption of the generated holes is reduced at the

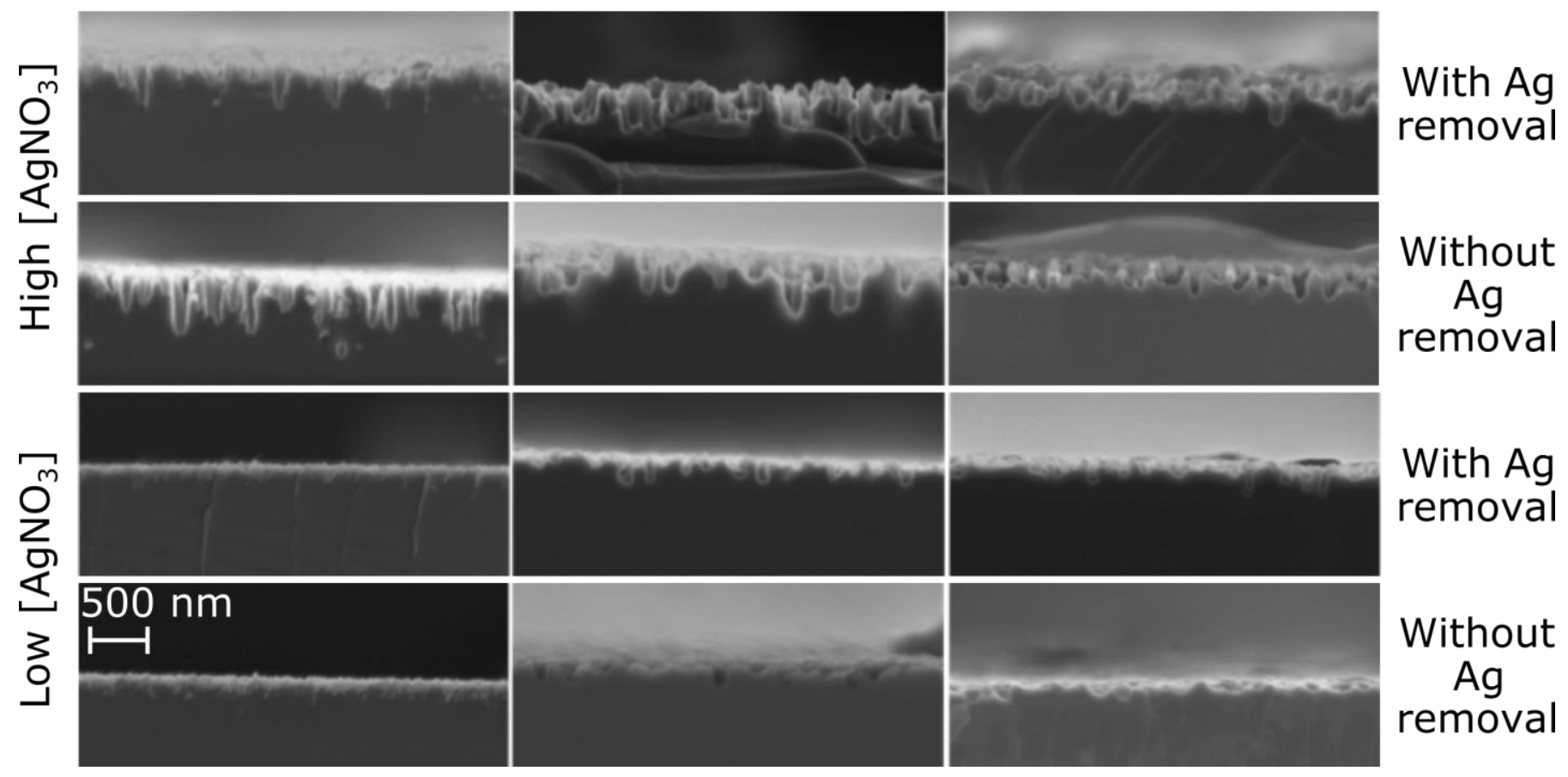

Fig. 2. SEM images of the ALD $\mathrm{Al}_{2} \mathrm{O}_{3}$-coated b-Si samples prior to and after $30 \mathrm{~s}$ or $60 \mathrm{~s}$ polishing. Higher AgNO 3 concentration in the first step results in needleshaped nanostructures, whereas lower $\mathrm{AgNO}_{3}$ concentration produces nanoporous surface. Polishing reduces the size of the nanostructures in all samples. The same scale bar applies to all images. 
nanoparticle-Si interface. Consequently, the excess holes diffuse to all silicon surfaces, which results in homogeneous oxidation and subsequent etching of the wafer [3], [7], [27]. Hence, the presence of Ag nanoparticles slightly increases the etch rate of silicon in the $\mathrm{HF} / \mathrm{HNO}_{3} / \mathrm{H}_{2} \mathrm{O}$ solution, which results in accelerated polishing of the nanostructures. The effect is more distinct within the SEM images of the low $\left[\mathrm{AgNO}_{3}\right]$ samples, which may be due to the larger dimensions of the needle-shaped $b$-Si on the high $\left[\mathrm{AgNO}_{3}\right]$ samples that hinder small changes from being as noticeable.

\section{B. Reflectance}

Since the MACE-parameters were observed to greatly affect the surface morphology, the analysis proceeds next to the optical properties of such b-Si nanostructures. Fig. 3a shows reflectance spectra of the b-Si samples that have not been polished. All samples show less than $10 \%$ reflectance in the whole inspected wavelength range between $300 \mathrm{~nm}$ and 1000 $\mathrm{nm}$. Especially, reflectance of the high $\left[\mathrm{AgNO}_{3}\right]$ samples is only $\sim 4 \%$ at the maximum. The needle-shaped $\mathrm{b}$ - $\mathrm{Si}$ on those samples acts as an effective refractive index gradient and efficiently reduces light reflection in a wide range of wavelengths, as reported also earlier for similar nanostructures [28], [29]. In the low $\left[\mathrm{AgNO}_{3}\right]$ samples, the graded index effect is equally effective at short wavelengths. However, since the nanoporous layer is thinner than the nanostructures on the high $\left[\mathrm{AgNO}_{3}\right]$ samples, the effect is weaker in the long wavelength range, which is seen as an increase in reflectance [30].

Fig. $3 \mathrm{~b}$ presents solar spectrum-weighted (AM1.5G) average reflectance of all the samples as a function of polishing time. Polishing increases reflectance of all samples, as expected based on the reducing nanostructure size (Fig. 2). The increase in reflectance is initially pronounced in the low $\left[\mathrm{AgNO}_{3}\right]$ samples, which is likely due to faster etching of the nanoporous structure compared to the larger needle-shaped structures on the high $\left[\mathrm{AgNO}_{3}\right]$ samples that have less surface area in contact with the chemicals. As the polishing proceeds, the difference between the high and low $\left[\mathrm{AgNO}_{3}\right]$ samples diminishes as the nanopores are eventually entirely removed and the surfaces become more similar, as was observed from the SEM images (Fig. 2).

On the other hand, the samples that were polished directly after b-Si formation (labelled as "without Ag removal") show overall slightly higher reflectance than the equivalents, from which the Ag nanoparticles were removed. The increased reflectance is attributed to the accelerated polishing of the samples with Ag nanoparticles, which was observed also by SEM imaging. Although the catalytic effect of nanoparticles on the polishing process was not as evident in the SEM images of the high $\left[\mathrm{AgNO}_{3}\right]$ samples, the difference in reflectance between those samples with and without Ag removal indicates that the phenomenon occurs also with higher $\mathrm{AgNO}_{3}$ concentration.

\section{Minority charge carrier lifetime}

From the optics perspective, as seen above, polishing of MACE-fabricated b-Si should be avoided as it increases
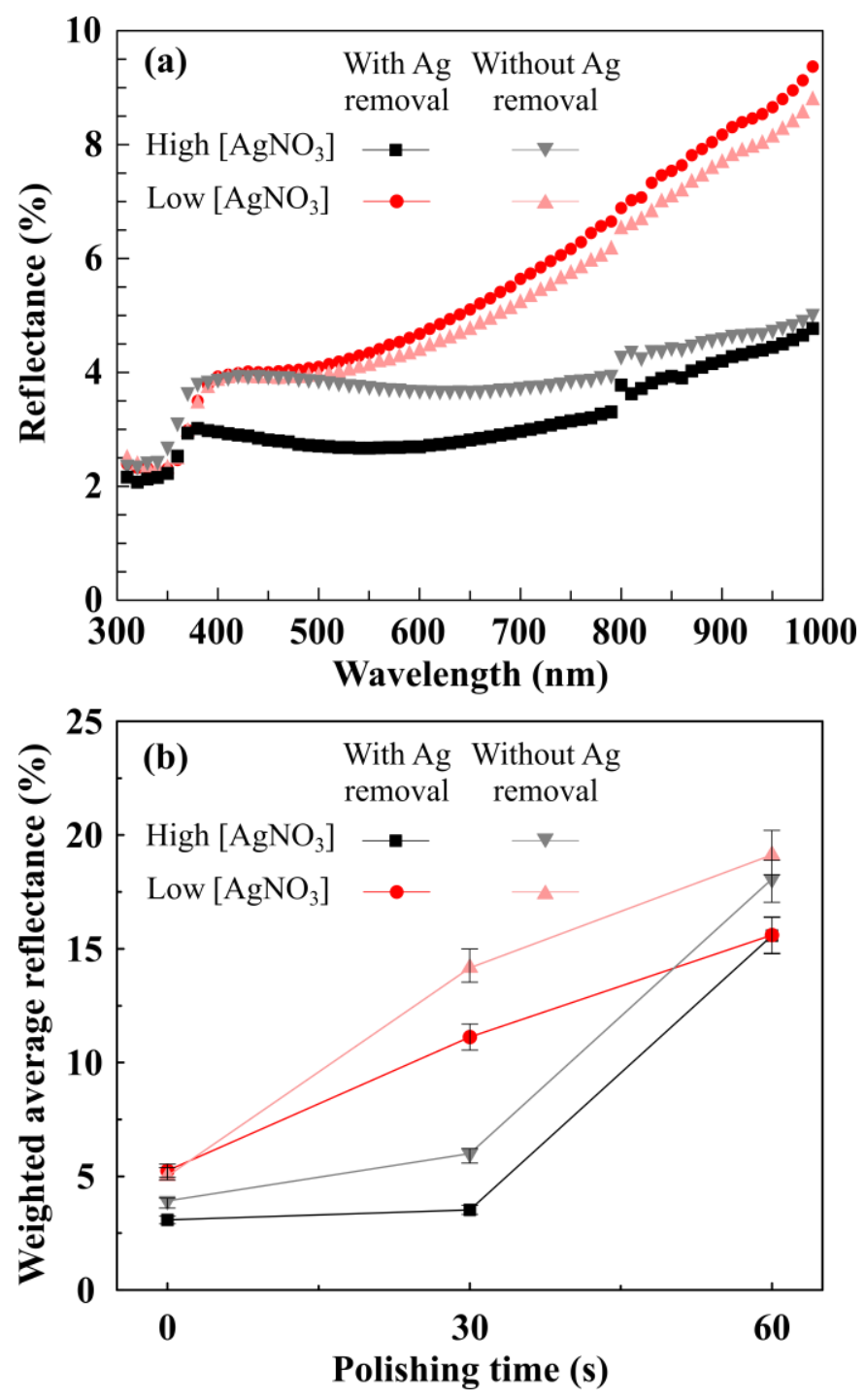

Fig. 3. (a) Reflectance spectra of the b-Si samples prior to polishing. The samples have an $\mathrm{ALD} \mathrm{Al}_{2} \mathrm{O}_{3}$-coating on the nanostructure. The spikes at 800 $\mathrm{nm}$ wavelength are due to change of a grating. (b) Solar spectrum-weighted average reflectance of the $\mathrm{b}-\mathrm{Si}$ samples as a function of polishing time in $\mathrm{HF} / \mathrm{HNO}_{3} / \mathrm{H}_{2} \mathrm{O}$ solution. The average has been weighted by the AM1.5G spectrum in the wavelength range of 300-1000 nm. Note the different scales on the y-axes.

reflectance. However, excellent optics do not necessarily guarantee high-performance solar cells if the electrical properties are simultaneously impaired. Therefore, recombination at the nanotextured surfaces after $\mathrm{ALD} \mathrm{Al}_{2} \mathrm{O}_{3}$ passivation is further investigated. Fig. 4a shows the effective minority charge carrier recombination lifetime of the same samples that have b-Si on both sides at an injection level of $10^{15}$ $\mathrm{cm}^{-3}$, which is a typical condition under one sun illumination. The figure reveals that all samples have an effective carrier lifetime on the order of hundreds of $\mu$ s even without polishing, which is sufficiently high for $>20 \%$-efficient PERC solar cells [31]-[33].

The $\mathrm{AgNO}_{3}$ concentration affects the behaviour of carrier lifetime as a function of polishing. In the high $\left[\mathrm{AgNO}_{3}\right]$ samples, polishing has only negligible effect on lifetime, which agrees with the observations of Chong et al. [13]. This indicates 

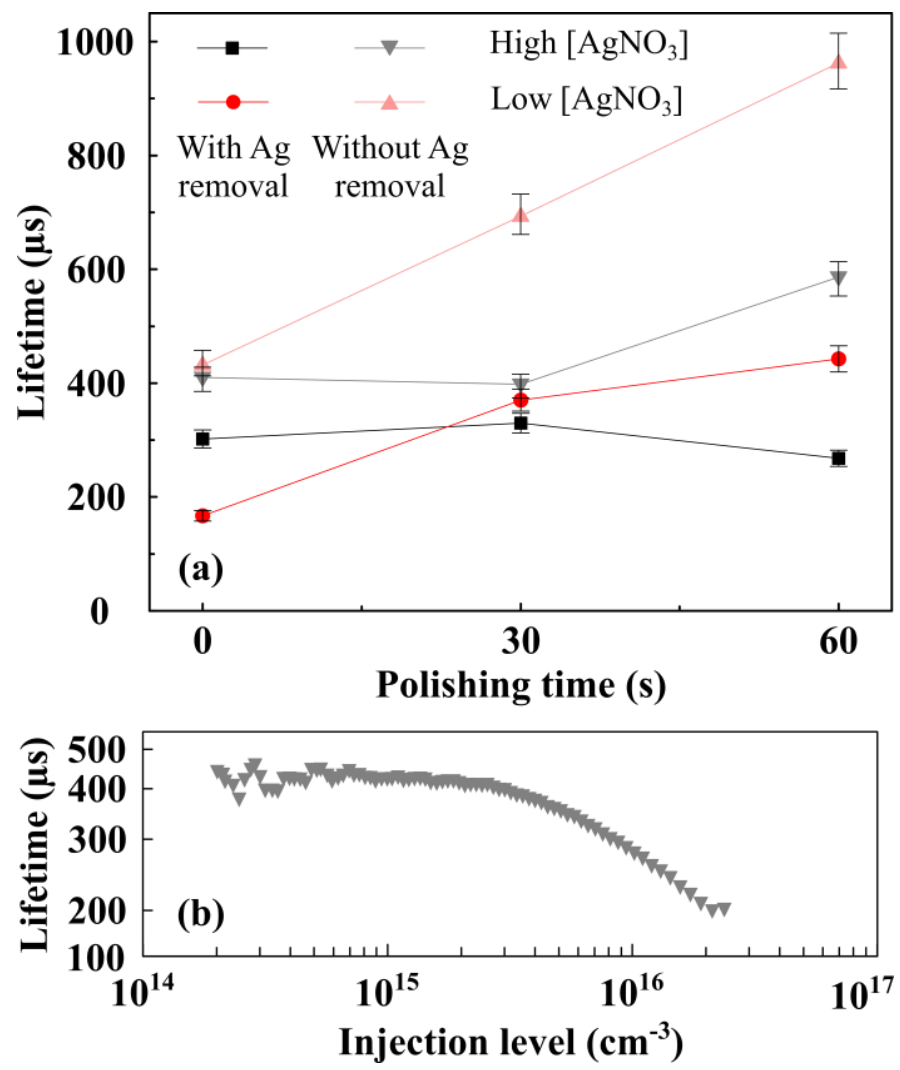

Fig. 4. (a) Effective minority charge carrier lifetime of the $\mathrm{ALD} \mathrm{Al}_{2} \mathrm{O}_{3}$ passivated b-Si samples as a function of polishing time. The lifetime values are reported at an injection level of $10^{15} \mathrm{~cm}^{-3}$. (b) Injection-dependent carrier lifetime of the non-polished high $\left[\mathrm{AgNO}_{3}\right]$ sample without $\mathrm{Ag}$ removal. Note the logarithmic axes in (b).

that the ALD thin film is capable of passivating needle-shaped b-Si efficiently independent of its dimensions and the reduction in nanostructure size by polishing provides no benefit for surface passivation. Hence, a polishing step is not a prerequisite for good electrical properties in MACE b-Si when using ALD, and surface recombination velocity of $30 \mathrm{~cm} / \mathrm{s}$ is achieved in combination with $3.9 \%$ reflectance without polishing (high $\left[\mathrm{AgNO}_{3}\right]$, without Ag removal), which is at the same level with earlier reports [12], [13].

Instead, the low $\left[\mathrm{AgNO}_{3}\right]$ samples show a trend of increasing lifetime as the polishing proceeds. This behaviour can be explained by the more porous surface of those samples (Fig. 2). Although the b-Si spikes on the high $\left[\mathrm{AgNO}_{3}\right]$ samples can be coated conformally with $\mathrm{ALD} \mathrm{Al}_{2} \mathrm{O}_{3}$ independent of their size, resulting in efficient surface passivation, the nanopores are more challenging to passivate due to their extremely large surface area and complex structure. Hence, removal of the porous layer and reduction of the surface area by polishing enables more conformal deposition of the thin film and results in more efficient surface passivation. However, the reduced surface recombination does not guarantee enhanced performance of the final device, since it is obtained at the expense of optical properties (Fig. 3b).

Surprisingly, the b-Si samples, from which the $\mathrm{Ag}$ nanoparticles were not removed in $\mathrm{HNO}_{3}$, show constantly higher lifetime than the samples with Ag removal, despite the potential risk of silver contamination. As discussed earlier, the surface is smoothened more efficiently when the nanoparticles are present during polishing. Hence, it is possible that also the high $\left[\mathrm{AgNO}_{3}\right]$ samples have a very thin nanoporous layer at the surface, which is removed by polishing, resulting in reduced SRV. Nevertheless, the lifetime improvement by the exclusion of the Ag removal step is more significant within the low $\left[\mathrm{AgNO}_{3}\right]$ samples, where the removal of the nanoporous layer is more critical to efficient surface passivation.

High carrier lifetime in the samples that did not experience the Ag removal step indicates that the bulk remained uncontaminated. This conclusion is supported by the shape of the injection-dependent lifetime, namely the constant carrier lifetime at low injection, measured from the samples, from which the nanoparticles were not removed in $\mathrm{HNO}_{3}$ (data for the non-polished high $\left[\mathrm{AgNO}_{3}\right]$ sample is shown as an example in Fig. 4b). Hence, the RCA cleaning that was performed prior to ALD may have removed the remaining nanoparticles. In addition to cleaning, the RCA solutions may have slightly altered the final morphology of $\mathrm{b}-\mathrm{Si}$, and hence, affected the optical and electrical properties of the nanostructures [29]. Nevertheless, the presented SEM images and all data correspond the properties at the same stage, i.e., after cleaning and thin film deposition. Alternatively, the temperature of annealing that was performed after $\mathrm{Al}_{2} \mathrm{O}_{3}$ deposition $\left(400{ }^{\circ} \mathrm{C}\right)$ was insufficiently high to activate silver-related defects and impair carrier lifetime in the bulk [20]. Typical solar cell processes may include steps that have higher thermal load, such as contact firing, which needs to be considered. Moreover, although RCA cleaning could also assist the prevention of other detrimental contaminants in solar cell production, it is not the current standard for PV industry. Hence, the effectiveness of the applied cleaning solutions needs to be carefully analysed and balanced with their cost.

\section{CONCLUSION}

This work demonstrated that a polishing step, which is typically applied after b-Si fabrication by MACE, is not a prerequisite for efficient surface passivation when the PECVD $\mathrm{SiN}_{x}$ is replaced with $\mathrm{ALD} \mathrm{Al}_{2} \mathrm{O}_{3}$. While polishing increased reflectance by reducing the nanostructure size, it had in general only a very modest effect on SRV. However, the $\mathrm{AgNO}_{3}$ concentration in the $\mathrm{AgNO}_{3} / \mathrm{H}_{2} \mathrm{O}$ solution, which was used to deposit Ag nanoparticles, had an effect on the porosity of the b$\mathrm{Si}$. Low $\mathrm{AgNO}_{3}$ concentration produced a porous surface that required smoothening to improve the electrical performance, which simultaneously impaired the optical properties. Hence, the $\mathrm{AgNO}_{3}$ concentration should be kept sufficiently high (in the $\mathrm{mmol} / \mathrm{L}$ range) to achieve low reflectance and to prevent formation of nanoporous $\mathrm{Si}$, which is challenging to passivate. Surprisingly, the highest lifetimes were achieved in samples, from which the $\mathrm{Ag}$ nanoparticles were not removed with $\mathrm{HNO}_{3}$, although the risk of metal contamination was higher. The reduced SRV was likely due to accelerated polishing of the nanostructure induced by the Ag nanoparticles, which was observed also as increased reflectance. The nanoparticles were likely removed in RCA cleaning after the nanotexturing process, which prevented the contaminants from impairing bulk 
lifetime. The results demonstrate that no trade-offs are required between optical and electrical properties of MACE b-Si by the application of ALD, when the MACE parameters are appropriately selected.

\section{ACKNOWLEDGMENT}

The authors would like to acknowledge the provision of facilities and technical support by Aalto University at OtaNano - Micronova Nanofabrication Centre.

\section{REFERENCES}

[1] "International technology roadmap for photovoltaic: Results 2016. 8th Edition, Mar. 2017."

[2] F. Toor et al., "Nanostructured silicon via metal assisted catalyzed etch (MACE): Chemistry fundamentals and pattern engineering," Nanotechnology, vol. 27, no. 41, pp. 1-12, 2016.

[3] Z. Huang, N. Geyer, P. Werner, J. De Boor, and U. Gösele, "Metalassisted chemical etching of silicon: A review," Adv. Mater., vol. 23, no. 2, pp. 285-308, 2011.

[4] X. Ye et al., "18.45\%-Efficient Multi-Crystalline Silicon Solar Cells with Novel Nanoscale Pseudo-Pyramid Texture," Adv. Funct. Mater., vol. 24, no. 42, pp. 6708-6716, 2014.

[5] Z. G. Huang et al., "One-step-MACE nano/microstructures for highefficient large-size multicrystalline Si solar cells," Sol. Energy Mater. Sol. Cells, vol. 143, pp. 302-310, 2015.

[6] K. Chen et al., "MACE nano-texture process applicable for both single- and multi-crystalline diamond-wire sawn Si solar cells," Sol. Energy Mater. Sol. Cells, vol. 191, no. July 2018, pp. 1-8, 2019.

[7] F. Es, M. Kulakci, and R. Turan, "An Alternative Metal-Assisted Etching Route for Texturing Silicon Wafers for Solar Cell Applications," IEEE J. Photovoltaics, vol. 6, no. 2, pp. 440-446, 2016.

[8] J. Oh, H. C. Yuan, and H. M. Branz, "An 18.2\%-efficient blacksilicon solar cell achieved through control of carrier recombination in nanostructures," Nat. Nanotechnol., vol. 7, no. 11, pp. 743-748, 2012.

[9] P. Repo et al., "Effective Passivation of Black Silicon Surfaces by Atomic Layer Deposition," IEEE J. Photolvoltaics, vol. 3, no. 1, pp. 90-94, 2013

[10] M. Otto, M. Kroll, T. Käsebier, R. Salzer, A. Tünnermann, and R. B. Wehrspohn, "Extremely low surface recombination velocities in black silicon passivated by atomic layer deposition," Appl. Phys. Lett., vol. 100, no. 19, pp. 1-5, 2012.

[11] I. T. S. Heikkinen, P. Repo, V. Vähänissi, T. Pasanen, V. Malinen, and H. Savin, "Efficient surface passivation of black silicon using spatial atomic layer deposition," in Energy Procedia, 2017, vol. 124, pp. 282-287.

[12] T. Rahman, R. S. Bonilla, A. Nawabjan, P. R. Wilshaw, and S. A. Boden, "Passivation of all-angle black surfaces for silicon solar cells," Sol. Energy Mater. Sol. Cells, vol. 160, pp. 444-453, 2017.

[13] T. K. Chong, K. J. Weber, K. M. Booker, and A. W. Blakers, "Characterization of MAE-textured nanoporous silicon for solar cells application: Optics and surface passivation," IEEE J. Photovoltaics, vol. 4, no. 5, pp. 1235-1242, 2014.

[14] F. Toor et al., "Metal assisted catalyzed etched (MACE) black Si: Optics and device physics," Nanoscale, vol. 8, no. 34, pp. 1544815466, 2016.

[15] Y. Jiang, H. Shen, T. Pu, and C. Zheng, "Improved passivation effect in multicrystalline black silicon by chemical solution pretreatment," Appl. Phys. A Mater. Sci. Process., vol. 124, no. 4, pp. $1-7,2018$.

[16] P. K. Parashar, S. A. Kinnunen, T. Sajavaara, J. J. Toppari, and V. K. Komarala, "Thermal atomic layer deposition of AlOxNy thin films for surface passivation of nano-textured flexible silicon," Sol. Energy Mater. Sol. Cells, vol. 193, pp. 231-236, 2019.

[17] D. T. Cao, L. T. Q. Ngan, T. Van Viet, and C. T. Anh, "Effect of $\mathrm{AgNO} 3$ concentration on structure of aligned silicon nanowire arrays fabricated via silver-assisted chemical etching," Int. J. Nanotechnol., vol. 10, no. 3/4, p. 343, 2013.
[18] R. Venkatesan, M. K. Arivalagan, V. Venkatachalapathy, J. M. Pearce, and J. Mayandi, "Effects of silver catalyst concentration in metal assisted chemical etching of silicon," Mater. Lett., vol. 221, pp. 206-210, 2018.

[19] F. Rollert, N. A. Stolwijk, and H. Mehrer, "Solubility, diffusion and thermodynamic properties of silver in silicon," J. Phys. D. Appl. Phys., vol. 20, no. 9, pp. 1148-1155, 1987.

[20] K. Graff, Metal Impurities in Silicon-Device Fabrication. Springer, 1995.

[21] F. Toor, J. Oh, and H. M. Branz, "Efficient nanostructured 'black' silicon solar cell by copper-catalyzed metal-assisted etching," Prog. Photovoltaics Res. Appl., vol. 23, no. 10, pp. 1375-1380, 2015.

[22] H. Saloniemi, T. Visti, S. Erìnen, A. Kiviranta, and O. Anttila, "Improvement of SC-1 Bath Stability by Complexing Agents," Phys. Scr., vol. 2002, no. T101, pp. 226-229, 2002.

[23] G. W. Gale et al., "Enhancement of Semiconductor Wafer Cleaning by Chelating Agent Addition," J. Electrochem. Soc., vol. 148, no. 9, p. G513, 2001.

[24] T. Pasanen, V. Vähänissi, N. Theut, and H. Savin, "Surface passivation of black silicon phosphorus emitters with atomic layer deposited SiO2/Al2O3 stacks," Energy Procedia, vol. 124, pp. 307312, 2017.

[25] D. R. Turner, "On the Mechanism of Chemically Etching Germanium and Silicon," J. Electrochem. Soc., vol. 107, no. 10, p. $810,1960$.

[26] E. S. Kooij, K. Butter, and J. J. Kelly, "Silicon Etching in $\mathrm{HNO}_{3} / \mathrm{HF}$ Solution: Charge Balance for the Oxidation Reaction," Electrochem. Solid-State Lett., vol. 2, no. 4, pp. 178-180, 1999.

[27] C. Chartier, S. Bastide, and C. Lévy-Clément, "Metal-assisted chemical etching of silicon in HF-H2O2," Electrochim. Acta, vol. 53, no. 17, pp. 5509-5516, 2008.

[28] W.-C. Wang, M.-C. Tsai, J. Yang, C. Hsu, and M.-J. Chen, "Efficiency Enhancement of Nanotextured Black Silicon Solar Cells Using Al2O3/TiO2 Dual-Layer Passivation Stack Prepared by Atomic Layer Deposition," ACS Appl. Mater. Interfaces, vol. 7, no. 19, pp. 10228-10237, 2015.

[29] T. P. Pasanen, H. S. Laine, V. Vahanissi, K. Salo, S. Husein, and H. Savin, "Impact of Standard Cleaning on Electrical and Optical Properties of Phosphorus-Doped Black Silicon," IEEE J. Photovoltaics, vol. 8, no. 3, pp. 697-702, 2018.

[30] C. C. Striemer and P. M. Fauchet, "Dynamic etching of silicon for broadband antireflection applications," Appl. Phys. Lett., vol. 81, no. 16, pp. 2980-2982, 2002

[31] H. Hieslmair, J. Appel, J. Kasthuri, J. Guo, B. Johnson, and J. Binns, "Impact of the injection-level-dependent lifetime on Voc, FF, ideality $\mathrm{m}, \mathrm{J} 02$ and the dim light response in a commercial PERC cell," Prog. Photovoltaics Res. Appl., vol. 24, pp. 1448-1457, 2016.

[32] J. Hofstetter, C. del Gañizo, H. Wagner, S. Castellanos, and T. Buonassisi, "Material requirements for the adoption of unconventional silicon crystal and wafer growth techniques for high-efficiency solar cells," Prog. Photovoltaics Res. Appl., vol. 24, pp. 122-132, 2016.

[33] P. Preis et al., "Towards $20 \%$ solar cell efficiency using silicon from metallurgical process route," Energy Procedia, vol. 55, pp. 589-595, 2014

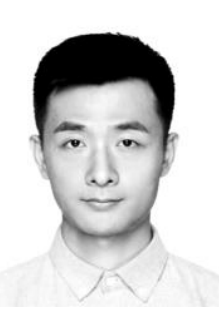

Kexun Chen received the D.Sc. (Tech.) degree in physical science and technology in 2018 from Soochow University, China. His research interests include surface texturization, especially nanostructured silicon, and surface passivation in silicon photovoltaics.

He is currently working as a postdoctoral researcher in the Department of Electronics and Nanoengineering, Aalto University, Finland. 


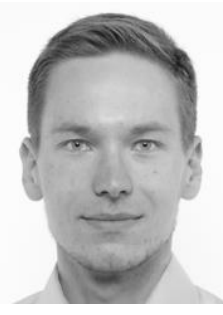

Toni P. Pasanen received the B.Sc. degree in electrical engineering and M.Sc. degree in micro and nanosciences from Aalto University, Finland, in 2015 and 2017 , respectively. $\mathrm{He}$ is currently pursuing towards the Ph.D. degree in micro and nanosciences in the same university.

His research is currently focused on implementation of nanostructured silicon in commercial silicon solar cells, surface passivation via atomic-layer-deposited thin films and defect engineering in silicon.

Ville Vähänissi received the D.Sc. (Tech.) degree in semiconductor technology in 2016 from Aalto University, Helsinki, Finland. His research interests include defect engineering in silicon, especially photovoltaics, as well as atomic layer deposition and its various applications in semiconductor devices.

He is currently working as a Staff Scientist at the Department of Electronics and Nanoengineering at Aalto University School of Electrical Engineering.

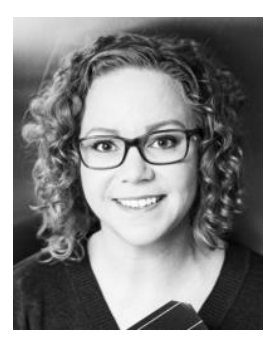

Hele Savin received the D.Sc. (Tech.) degree in semiconductor technology in 2005 from Aalto University, Finland.

Her research interests focus on material research in semiconductors, more specifically defect engineering in silicon, nanostructured silicon, light-induced degradation and silicon photodetectors.

She is currently an Associate Professor in the Department of Electronics and Nanoengineering, Aalto University, Finland. 